\title{
The Significance of Low Testosterone Levels in Obese Men
}

\author{
Carla Pelusi • Renato Pasquali
}

Published online: 19 August 2012

(C) Springer Science+Business Media, LLC 2012

\begin{abstract}
Low testosterone is frequently found in obese men over all ages. The relationship between obesity and low testosterone levels in men is complex and apparently bidirectional. Low testosterone and SHBG levels predict the development of central obesity and are associated with an increased risk of developing metabolic syndrome and type 2 diabetes and higher mortality rate for cardiovascular disease. By contrast, obesity predicts low total and free testosterone levels. Several mechanisms interfering with the hypothalamic pituitary gonadal axis have been suggested as responsible for low testosterone production in obese subjects without, however, any clear understanding. Life-style measures achieving a substantial weight loss may increase testosterone levels, whereas clear data on whether exogenous testosterone treatment in obese men, without an established hypogonadic state, may improve body fat content, visceral adiposity and insulin resistance are still missing. Further studies on the pathophysiological mechanisms and on the efficacy of testosterone treatment in obese men with low testosterone levels are needed.
\end{abstract}

Keywords Obesity $\cdot$ Testosterone $\cdot$ Men

C. Pelusi $\cdot$ R. Pasquali

Division of Endocrinology, S. Orsola-Malpighi Hospital, University Alma Mater Studiorum,

Bologna, Italy

C. Pelusi $(\triangle)$

Department of Medical and Surgical Science,

Division of Endocrinology, University Alma Mater Studiorum,

S. Orsola-Malpighi Hospital,

Via Massarenti 9,

Bologna, Italy

e-mail: carla.pelusi2@unibo.it

\section{Introduction}

Obesity is a heterogeneous disorder related to environmental and genetic factors, whose incidence has dramatically increased. According to the World Health Organization worldwide data for 2008, there are more then 1.5 billion people who are overweight and nearly 200 million men who are obese [1]. This condition has a profound impact on health, particularly for its well-known comorbidities such as type 2 diabetes and cardiovascular disease, etc. Approximately half of obese men may present with lower than normal testosterone levels, which may play a role in the pathophysiology of metabolic and cardiovascular comorbidities by impairing their quality of life $[2 \cdot \bullet]$.

Several epidemiological studies have established an inverse correlation between obesity and serum total and free testosterone levels in men of all ages [3-6], however, although many underlying pathophysiological mechanisms have been proposed, many more need to be elucidated.

The relationship between obesity and low testosterone levels appears to be complex and multifactorial. Obese men may present with abnormal levels of reproductive hormones due to changes in their secretion and metabolism, alterations in their transport and/or action at target tissues. Insulin resistance with compensatory hyperinsulinemia with the increased release from adipose tissue of several adipokines and cytokines, and higher estradiol promotion rate due to increase aromatase activity, which in turn alters both directly or indirectly the hypothalamic pituitary gonadal axis, have been suggested to be a major responsibility for low testosterone levels in obese subjects [7]. Finally, obesity and particularly central adiposity are potent risk factors for obstructive sleep apnea (OSA), which per se affects testosterone levels regardless of the degree of excess of body weight [8].

Although it is reported that obesity is associated with profound alterations in testosterone production rate and metabolic clearance, it is also true that, by contrast, low 
testosterone levels in primary or secondary hypogonadic states may in turn lead to increase visceral adiposity and insulin resistance. In this context, the deficit of testosterone is further emphasized by the fact that testosterone treatment in hypogonadic men may improve insulin sensitivity and fat content $[2 \bullet \bullet, 9]$.

This review will focus on the recent findings on the relationship between testosterone levels and obesity. We briefly summarize the current data on the epidemiology, the putative mechanisms and therapeutic implications.

\section{Low Testosterone Levels and Obesity: Evidence from Clinical and Epidemiological Studies}

In males, circulating testosterone blood levels have been shown to be influenced by body weight and composition. In particular, an inverse correlation between body composition and both total testosterone and SHBG and, to a lesser extent, free circulating testosterone has been described in men of different ages [5].

This correlation becomes significantly greater in the presence of another component of the metabolic syndrome, resulting in a more severe decrease of testosterone blood levels [10-12].

The decrease in testosterone levels appears to be more pronounced in men with abdominal adipose fat distribution since waist circumference and waist to hip ratio (WHR), indirect measurements of visceral body fat distribution, have been negatively associated with both total and free testosterone and SHBG levels [13, 14, 15•].

Recent data from the Massachusetts Male Aging Study (MMAS) [16] and the European Male Aging Study (EMAS) [17] performed in large groups of middle-aged and elderly men have shown that body mass index (BMI) and waist circumference or WHR measurements are independently associated with decreased values of both total and free testosterone.

The relationship between total and free testosterone and SHBG levels with visceral adiposity has been examined with more accurate measurements of abdominal fat distribution such as dual-energy x-ray absorptiometry (DEXA) and magnetic resonance imaging. Nielsen and colleagues [18] showed that in a group of 783 Danish men, aged 20$29 \mathrm{yrs}$, the amount of visceral adipose tissue was independently and inversely correlated with total and free testosterone, suggesting a direct effect of visceral adipose tissue on circulating testosterone levels.

Therefore the total amount of fat mass and specifically an increase of visceral adipose tissue are both responsible for low testosterone levels; however, whether low testosterone levels precede or are the consequence of obesity has not been fully elucidated.
Several studies have analyzed the longitudinal relationship of obesity as a modifier of sex hormone concentrations. In the MMAS, the authors examined whether changes in adiposity predicted follow-up modification- of androgen concentrations during a period of approximately 9 years, and found that obesity could predict the decline in total and free testosterone and SHBG over time, regardless of whether obesity was defined by BMI or by waist circumference. It was also shown that men changing from normal weight to obese over time had a significant reduction in total and free testosterone and SHBG levels. On the other hand, men who were consistently obese had a significantly greater rate of decline in hormone levels during the study period [19].

Whether a baseline endogenous testosterone blood level could predict adiposity was also investigated. Khaw and Barrett-Conner [14] found that total testosterone and SHBG were inversely related to central adiposity estimated with WHR over a follow up period of 12-15 years. Similarly, in a cohort of Japanese-American men followed for 7.5 years, low baseline testosterone levels significantly predicted an increase of intra-abdominal fat by CT scan [20]. These data have been confirmed by the Multi-Ethnic Study of Atherosclerosis in which, in a mixed racial/ethnic group of 2708 men, the authors showed a negative association of total testosterone and SHBG levels with WHR at baseline and at follow up [15•]. In particular, the authors found an increasing degree of obesity over time in men with lower baseline testosterone and SHBG levels. Interestingly, this association also remained significant when testosterone was adjusted for SHBG levels.

\section{Prevalence of Low Testosterone in Obesity}

The prevalence of low testosterone has been evaluated by several authors in a large population of middle-aged and older men reaching different numerical conclusions, depending on whether free or total testosterone was used to make the diagnosis, however all showed an increasing rate of hypotestosteronemia with increasing age, BMI and according to the presence of comorbidities, including diabetes and metabolic syndrome.

This has been particularly defined by two large studies, the MMAS [21] and the EMAS [22].

Only one cross-sectional study, the Hypogonadism In Males Study (HIM), analyzed the prevalence of low testosterone levels in a selected population of subjects stratified by BMI. This study enrolled a cohort of 1849 men, aged 45$96 \mathrm{yrs}$, with the aim of investigating the association between obesity and low testosterone, and of comparing the prevalence of low testosterone with obesity and diabetes separately and together. The data showed a 40 percent prevalence of low testosterone, based on total and free testosterone levels, 
in obese non-diabetic men. In addition, in men with diabetes, whether obese or not, lower levels of testosterone than in non-diabetic men across all BMI categories were reported, and in both groups testosterone levels significantly decreased as BMI increased $[2 \bullet \bullet]$.

\section{Pathophysiological Mechanisms of Low Testosterone in Obese Men}

Several pathophysiological mechanisms have been suggested as responsible for low testosterone in obese males. Besides the known effect of massive obesity in inducing a partial hypogonadotrophic hypogonadism due to a reduction in the amplitude but not frequency of spontaneous LH pulse [23], many other factors appear to be involved in determining low testosterone in obese men (Fig. 1).

\section{Insulin Resistance}

Obesity, in particular visceral adiposity, is closely associated with insulin resistance and compensatory hyperinsulinemia. Insulin excess is known to inhibit hepatic SHBG secretion in vitro [24] and in vivo [25], thus explaining the decrease of SHBG levels frequently found in obese male subjects. However, other mechanisms related to insulin resistance and associated hyperinsulinemia may be responsible for low testosterone levels in insulin resistant men that cannot only be explained by changes in SHBG blood levels. In fact, a functional defect at different levels of the hypothalamicpituitary gonadal axis in the presence of an insulinresistant state has been reported. Pitteloud and colleagues found that hyperinsulinemia may directly exert a suppressive effect on testicular Leydig cell steroidogenesis [26]. Moreover, it has been reported that mice with a selective neuron deletion of the insulin receptor gene display a decrease of LH blood concentrations by $60-90 \%$ which in turn leads to low testosterone levels

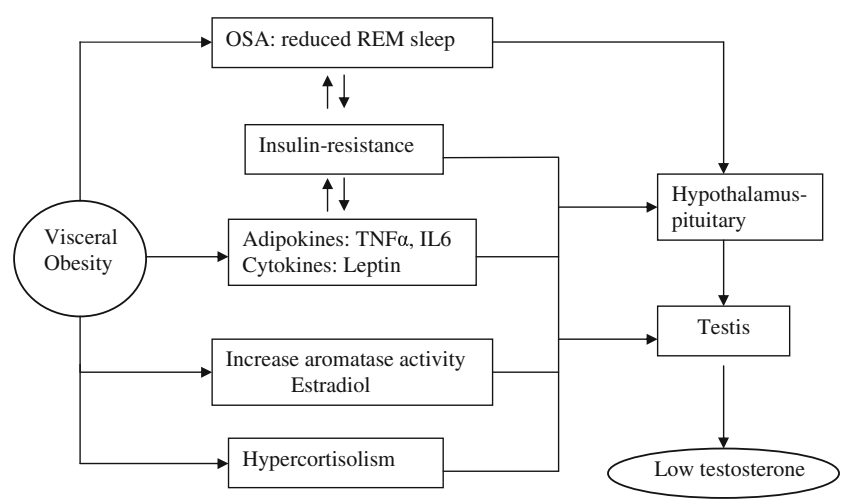

Fig. 1 Mechanisms underline low testosterone in obesity
[27]. By contrast, a facilitation of GnRH secretion was reported in vitro after incubation of hypothalamic neurons with insulin [28, 29].

These data suggest a positive relationship between testosterone levels and insulin sensitivity in men that are independent of SHBG production.

\section{Estrogens}

In the mesenchymal cells and preadipocytes of adipose tissue of male subjects, androgens can be converted to estrogens by aromatase. The estrogen production rate is closely related to body weight as the increase in adipose tissue mass leads to increased aromatase activity [30, 31]. This increase in circulating estradiol levels may in turn lead to an inhibition of the hypothalamic GnRH secretion and LH pulsatility which results in a reduction of gonadal testosterone production [32]. Moreover, estrogen excess may also directly inhibit gonadal 17-alphahydroxylase and 17,20 lyase activity, thus inhibiting Leydig cell steroidogenesis [33].

On the other hand, available data on the estradiol blood concentrations in obese males are contradicting. In fact, few studies have really shown higher than normal estradiol concentrations in obese men compared with non-obese men $[23,30,34]$ and a statistically positive association between estradiol concentration with BMI and waist circumference $[5,35]$, whereas other more recent studies did not $[2 \bullet \bullet, 36]$.

Interestingly, it has also been shown that short term treatment with aromatase inhibitors in morbidly obese subjects may improve testosterone levels [37], which strongly supports a direct role of estrogen excess in lowering testosterone through factors increasing aromatase activity in obesity.

\section{Adipokines and Cytokines}

The adipose tissue is made up of adipocytes and macrophages that are capable of producing adipose-derived hormones such as adipokines and cytokines which exert both paracrine and endocrine activities. This specifically applies to visceral fat tissue that is associated with an increase in adipokines and cytokines which play an important role in determining both local and generalized low-grade inflammation state [38]. Several of these adipokines have been involved in the development of insulin resistance and, additionally, have been shown to increase oxidative stress in the testes [39]. Among the adipokines, leptin and adiponectin will be addressed in this review.

Leptin is primarily secreted by adipocytes and its function is to reduce appetite and increase energy expenditure in the body. In obese men, leptin levels are not only progressively elevated with increasing body weight and excess 
body fat tissue, but also display an inverse correlation with testosterone levels [40].

In vitro and in vivo studies have in fact shown that leptin affects testosterone production by directly inhibiting Leydig cell function by blocking the conversion of 17-OHprogesterone into testosterone [40, 41] and indirectly, at hypothalamic level, by altering gonadotropin releasing hormone $(\mathrm{GnRH})$ neuronal function through modulation of hypothalamic Kiss 1 gene expression, an important regulator of the neuroendocrine network regulating the gonadal axis. In fact, leptin activates the long isoform leptin receptor $\mathrm{b}(\mathrm{LRb})$ expressing kisspeptin neurons in the arcuate nucleus that are the most potent activators of GnRH neurons, thus stimulating the release of LH and FSH by the pituitary gland [42]. Studies in vitro and in vivo have also shown that serum leptin is reduced after testosterone administration [43] which is consistent with a bidirectional regulation of the leptin gonadal function.

Besides these effects at different levels of the hypothalamic pituitary gonadal axis, leptin has also been found to favor macrophage secretion of pro-inflammatory cytokines, therefore promoting an insulin-resistance state, which further supports the role of compensatory insulin excess at both hypothalamic and gonadal levels [44].

Adiponectin, a circulating hormone predominantly secreted by mature adipocytes that has an important role in regulating energy metabolism and insulin sensitivity [45] may also interact with testosterone levels in men. Adiponectin plays an important protective role in the development of the metabolic syndrome and cardiovascular disease [46]. Notably, circulating levels of adiponectin are lower in obese subjects compared with normal weight people and its levels are inversely correlated with abdominal fat mass [47]. In addition, a significant correlation has been reported between adiponectin and testosterone levels in males. Testosterone seems to negatively influence adiponectin concentrations, as documented in cases of supraphysiological androgen administration; however, it may favor increased adiponectin levels in the case of adequate androgen administration [48].

Obesity is also associated with increased in proinflammatory cytokines release mainly from adipose tissuederived macrophages such as tumor necrosis factor $\alpha(\mathrm{TNF} \alpha)$, Interleukin-6 (IL6), Interleukin-8 (IL-8) and many others.

Cytokines, as well as adipokines, may influence testosterone levels by directly interfering with the hypothalamic pituitary gonadal axis and indirectly altering insulin transduction pathway.

In vitro studies have shown that TNF $\alpha$ and IL6 are able to suppress GnRH and LH secretion thus reducing peripheral testosterone secretion $[49,50]$.

Elevated TNF $\alpha$ in adipose tissue is known to contribute to insulin resistance together with IL6 by inhibiting insulin receptor transduction in tissue [51]. Recently, Gautier and colleagues [36] showed that IL-6 is associated with low total and bioavailable testosterone levels in dysmetabolic men, reinforcing the important role of low-grade visceral fat inflammation in obesity related to low testosterone levels in males.

Therefore, although the biological role of the increase in macrophage infiltration into adipose tissue and consequent cytokines release in obesity need to be fully established, we can speculate that these pro-inflammatory mediators may contribute to lower testosterone levels in obese men directly or indirectly favoring an insulin resistance state.

\section{Obstructive Sleep Apnea}

Obese men, particularly those with abdominal phenotype, frequently present with obstructive sleep apnea (OSA), which is characterized by obstruction of the upper airways. OSA may play an independent role with respect to obesity or excess visceral fat in decreasing testosterone levels. In healthy men, testosterone is secreted with specific patterns, characterized by increasing levels during sleep with a maximum around the time of awakening and lower levels during the day. In addition, sleep has a strong influence on testosterone secretion regardless of the time of the day [8]; in particular, it has been demonstrated that the first REM episode is specifically related to the rise in testosterone levels. The mechanisms responsible for the sleep-related rise in testosterone levels are unknown although it has been suggested they are primarily dependent on LH levels. A reduced nocturnal rise in testosterone levels has been described in disturbed sleep, such as low sleep efficiency or OSA. Studies performed in young adults have shown that during total deprivation of sleep androgen concentrations declined significantly, whereas once sleep was recovered testosterone levels promptly returned to normal $[52,53]$. We have also shown that in patients with obesity and OSA the severity of hypoxia during sleep hours may be an additional factor in reducing testosterone levels, regardless of BMI and abdominal fatness [54]. This may contribute in worsening metabolic abnormalities which in men with OSA exceed those expected on the basis of the degree of obesity and pattern of fat distribution.

\section{Relative Hypercortisolism}

There is an increased turnover and production of glucocorticoids in obesity. This increased glucocorticoid flux has been suggested to reflect an abnormal control of the hypothalamic pituitary adrenal axis in obese patients, which may determine an inhibition of the hypothalamic-pituitary gonadal 
axis. This topic has been extensively reviewed in a recent review (for more details, see Pasquali et al. [55]).

\section{How to Measure Testosterone Level in Obese Males}

In general, the biochemical diagnosis of androgen deficiency characterized by subphysiological serum levels of total testosterone remains a controversial issue due to the variety and relative diagnostic accuracy of assays usually available in most laboratories. Total testosterone concentrations are measured by semi- automated radioimmunoassays, immunometric assays, or liquid chromatography tandem mass spectrometry. The widely used methods electro chemiluminescent immunoassay and liquid chromatography tandem mass spectrometry have been compared, showing no significant differences in values usually found in the male physiological range [56].

However, there is general agreement that total testosterone might not reflect the true androgen status. Testosterone circulates mostly bound to two plasma proteins: approximately 50 $60 \%$ of the hormone is bound with high affinity to SHBG, while $40-50 \%$ is loosely bound to albumin and $2 \%$ is unbound. Total testosterone levels are influenced by SHBG whose levels can be altered by different conditions or diseases, such as aging, obesity, diabetes, hyper- and hypothyroidism, and acromegaly, as well as by certain medications [57]. In the presence of obesity SHBG may be variably reduced as a consequence of the coexistent insulin-resistant state [25], therefore the measurement of total testosterone may not be diagnostic in obese men, in whom clinicians should evaluate eventually the bioavailable or free testosterone fraction.

Since the measurement of free testosterone by radioimmunoassay has been criticized due to the lack of accuracy and linearity, free testosterone values, calculated from total testosterone, SHBG and albumin using the equilibrium -binding theory or empirical equations, should be preferably used [58]. However, normal ranges for free and bioavailable testosterone levels in healthy young men are still undefined and in addition they may vary among laboratories and assays used [57, 59]. In addition, there is evidence that testosterone blood values may depend on some genetic background. In fact, a recent meta-analysis of genome wide association studies revealed novel genetic variations within the SHBG gene and on the $\mathrm{X}$ chromosome which significantly affect circulating testosterone concentrations in men. In particular, one of the identified genetic variations was associated with an alteration in SHBG binding affinity for testosterone and the measured free testosterone concentrations $[60 \bullet \cdot$. The clinical usefulness of these genetic variations remains to be elucidated since they may impact testosterone bioavailability and action at target tissue levels. Interestingly, these data open a new prospective in the identification of men with low testosterone levels in whom genetic of SHBG as well as its circulating blood levels should be taken into account.

\section{The Meaning of Low Serum Testosterone Levels in Obese Males}

Low Testosterone as a Risk Factor for Metabolic Syndrome and Type 2 Diabetes

Several longitudinal population studies analyzing the association between testosterone and the metabolic syndrome revealed that low baseline testosterone concentrations in middle-aged and older men are a strong predictor for the incidence of the metabolic syndrome and future development of type 2 diabetes [61-66]. This association has also been reported in young men aged 20-39 years [67] regardless of race and/or ethnicity [10].

Furthermore, the MMAS [61] and a Finish study conducted by Laaksonen and colleagues [64] demonstrated that the relationship between testosterone and future development of metabolic syndrome and diabetes was relatively independent of adiposity. Similar findings were also reported by the Third National Health and Nutrition Survey (NHANES III) where 1413 adult men were analyzed [68]. This study showed that men in the lowest tertile of either free or bioavailable testosterone, but not total testosterone, are approximately four times more likely to develop diabetes compared with those in the third tertile after adjustment for adiposity, age, race and ethnicity. To further reinforce this perspective, Muller and colleagues [69] showed that higher testosterone and SHBG levels in aging males were independently associated with a higher insulin sensitivity and a reduced risk of the metabolic syndrome, regardless of insulin levels and parameters of body composition, which suggests that normal androgen status may be protective against the development of the metabolic syndrome.

On the other hand, Laaksonen et al. [64] examined whether changes in metabolic status predicted follow up levels and changes of sex hormone concentrations in a group of 685 men aged 42-60 years during a period of approximately 11 years. The authors showed that men with the metabolic syndrome were 2.6-2.9 times more likely to develop hypogonadism than those without it. In addition, those developing the metabolic syndrome during the follow up had a three fold higher risk of becoming hypogonadic, while in those men who had the metabolic syndrome at both baseline and during the follow up had and continued to have a metabolic syndrome during the study, the relative risk was 5.7-7.4 times higher. 
Low Testosterone as a Risk Factor for Cardiovascular Disease and All Causes of Mortality

Several studies analyzing the impact of low testosterone levels on cardiovascular diseases, revealed that decreasing testosterone levels were associated with an increased incidence of atherosclerosis [70], stroke, or transient ischemic attacks [71] and with higher mortality rate, largely due to cardiovascular disease, particularly in aged men [67, 72, 73].

An inverse relationship between carotid artery intima-media thickness, an independent marker of future adverse events for cardiovascular disease, and testosterone levels has been reported in different populations including relative young or aged men [74], men with diabetes [75] and finally overweightobese men with glucose intolerance [76]. This relationship was independent of age, BMI and other metabolic abnormalities [77]. An additional prospective study of men aged 73-91 found a marked progression of the degree of carotid intima media thickness over a four-years follow-up in subjects characterized by the lowest testosterone values at baseline [78].

In a prospective population-based study, total and bioavailable testosterone deficiency in aged men was associated with increased risk of death over the following 20 years, independently of other risk factors and pre-existing health condition [79]. In particular, the authors found that men with total testosterone levels in the lowest quartile were $40 \%$ more likely to die than those in the highest quartile, independent of age, adiposity, and lifestyle. This association was also independent of the presence of metabolic syndrome, diabetes, and prevalent cardiovascular diseases. In casespecific analyses, low testosterone predicted increased risk of cardiovascular disease mortality but was not significantly related to cancer death. These data confirmed those of the European Prospective Investigation Into Cancer in Norfolk (EPIC-Norfolk) case-control study that revealed an inverse relationship between endogenous testosterone concentration at baseline and mortality for all causes [70].

\section{Interventional Studies on Obese Men with Low Testosterone Levels: Effect of Weight Loss on Testosterone Levels}

The preferred way to improve testosterone levels in obese men should be life style intervention. In fact, although the data regarding the effect of weight loss on sex steroids in men have been conflicting, the majority of them have shown that this hormonal abnormality can be reversed by significant weight reduction. Weight loss achieved by dietary restriction [80-83] or bariatric surgery in humans, especially in morbidly obese men, has been reported to improve insulin sensitivity and androgen levels, with an increase in total testosterone to approximately $50 \%$ and free testosterone from 12 to $43 \%$ [84,
85]. However, weight reduction has been associated either with an increase $[34,86]$ or no influence on SHBG blood concentrations [83], which indirectly suggests that the increased androgen levels obtained after weight loss may not be only the consequence of changes in hormone transport binding. On the other hand, Niskanen and colleagues have also demonstrated that rapid weight loss with a very low calorie diet followed by successful weight maintenance for 12 months in abdominally obese men with the metabolic syndrome lead to a substantial increase in total and free testosterone as well as SHBG levels [87]. These findings are also supported by animal studies in which it was reported that a high calorie diet caused a decrease in serum testosterone levels together with significant weight gain [88], whereas hypocaloric dieting aimed at reversing excess body weight was able to improve serum testosterone levels to normal levels [89]. By contrast, it should be taken into consideration that negative studies on the impact of weight loss on both total and free testosterone levels have been published $[90,91]$, which reinforce the need of large long term randomized control studies.

\section{Intervention Studies on Obese Men with Low Testosterone Levels: Effect of Testosterone on Body Composition and Insulin-Resistance}

Testosterone replacement therapy administered to established hypogonadic patients has been proven to achieve beneficial effects on body composition by reducing the amount of visceral fat content and by increasing lean body mass, and improving most of the metabolic comorbidities such as insulin sensitivity and dyslipidemia [92]. On the other hand, studies conducted in men with prostate cancer, where androgen deprivation therapy was used, showed an increased accumulation of abdominal fat mass and an impairment of insulin sensitivity [93].

The rationale of testosterone effects have been explained by in vitro studies in culture cells where androgens proved to promote myogenic differentiation of multipotent mesenchymal stem cells and to inhibit their differentiation into the adipogenic lineage [94, 95].

Exogenous testosterone administration as a treatment for obesity has been examined in two double-blind studies and a few case reports. Two decades ago, Marin and colleagues treated 23 and 17 middle-aged obese men without diabetes with moderate doses of transdermal preparations of testosterone for 8 and 9 months respectively. Testosterone treatment reduced both visceral fat amount, evaluated by CT scan, and insulin resistance, measured by euglycemic glucose clamp [96, 97].

Since then, several other studies have been performed mainly in aged men with late onset hypogonadism with lownormal testosterone levels. Besides using different 
testosterone doses and treatment duration, these studies informally confirmed the effect of testosterone in reducing body fat mass and increasing lean body mass, whereas conflicting results on changes in visceral fat mass, insulin levels and insulin-resistance have been reported. These topics have been extensively reviewed in several recent review (more details in $[98,99 \bullet])$. These discrepancies indicate that more accurate and selective population-based long-term studies are needed to clarify the potential benefit of testosterone treatment in obese men with low testosterone levels.

\section{Conclusions}

In summary, several related mechanisms have been suggested to explain low testosterone in men with obesity. Whether low sex steroid levels precede or are the consequence of obesity is still unknown; however, it is clear that both conditions are unsafe since low testosterone and obesity per se are associated with an increased risk of developing the metabolic syndrome and cardiovascular disease and with higher mortality rates.

There is still no consensus on how to treat obese men with low testosterone with life style intervention in addition or not to androgen supplementation. Short term replacement therapy with exogenous testosterone may be considered initially, although it cannot replace long term lifestyle measures including physical activity.

Doses and treatment periods should be different from established hypogonadic patients in whom well-known dosage regimes and lifelong therapy are needed. Moreover, data regarding the chronic use of androgen supplementation in middle aged obese men in term of efficacy and safety are still missing.

Pathophysiological studies in obese subjects are needed to clarify the endocrine function of adipose tissue, that seems to have a dominant role in altering, either directly or indirectly, the hypothalamic pituitary gonadal activity, and therefore helping to find a more appropriate treatment for this condition.

Disclosure No potential conflicts of interest relevant to this article were reported.

\section{References}

Papers of particular interest, published recently, have been highlighted as:

- Of importance

•• Of major importance

1. Finucane MM, Stevens GA, Cowan MJ, Danaei G, Lin JK, Paciorek CJ, et al. National, regional, and global trends in bodymass index since 1980: Systematic analysis of health examination surveys and epidemiological studies with 960 country-years and 9.1 million participants. Lancet. 2011;377:557-67.

2. •- Dhindsa S, Miller MG, McWhirter CL, Mager DE, Ghanim H, Chaudhuri A, et al. Testosterone concentrations in diabetic and nondiabetic obese men. Diabetes Care. 2010;33:1186-92. The authors demostrated the prevalence of subnormal testosterone levels in patients with obesity and diabetes separatly and together. In nondiabetic men they showed an increase in prevalence of low testosterone across all BMI categories reinforcing the role of obesity per se in reducing testosterone levels.

3. Gapstur SM, Gann PH, Kopp P, Colangelo L, Longcope C, Liu K. Serum androgen concentrations in young men: a longitudinal analysis of associations with age, obesity, and race. The cardia male hormone study. Canc Epidemiol Biomarkers Prev. 2002;11:1041-7.

4. Jensen TK, Andersson AM, Jorgensen N, Andersen AG, Carlsen $\mathrm{E}$, Petersen $\mathrm{JH}$, et al. Body mass index in relation to semen quality and reproductive hormones among 1,558 danish men. Fertil Steril. 2004;82:863-70.

5. Rohrmann S, Shiels MS, Lopez DS, Rifai N, Nelson WG, Kanarek $\mathrm{N}$, et al. Body fatness and sex steroid hormone concentrations in us men: results from nhanes iii. Canc Causes Contr. 2011;22:1141-51.

6. Couillard C, Gagnon J, Bergeron J, Leon AS, Rao DC, Skinner JS, et al. Contribution of body fatness and adipose tissue distribution to the age variation in plasma steroid hormone concentrations in men: the heritage family study. J Clin Endocrinol Metab. 2000;85:1026-31.

7. Pasquali R. Obesity and androgens: facts and perspectives. Fertil Steril. 2006;85:1319-40.

8. Axelsson J, Ingre M, Akerstedt T, Holmback U. Effects of acutely displaced sleep on testosterone. J Clin Endocrinol Metab. 2005;90:4530-5.

9. Grossmann M, Gianatti EJ, Zajac JD. Testosterone and type 2 diabetes. Curr Opin Endocrinol Diabetes Obes. 2010;17:247-56.

10. Kupelian V, Hayes FJ, Link CL, Rosen R, McKinlay JB. Inverse association of testosterone and the metabolic syndrome in men is consistent across race and ethnic groups. J Clin Endocrinol Metab. 2008;93:3403-10.

11. Kaplan SA, Meehan AG, Shah A. The age related decrease in testosterone is significantly exacerbated in obese men with the metabolic syndrome. What are the implications for the relatively high incidence of erectile dysfunction observed in these men? J Urol. 2006;176:1524-7.

12. Brand JS, van der Tweel I, Grobbee DE, Emmelot-Vonk MH, van der Schouw YT. Testosterone, sex hormone-binding globulin and the metabolic syndrome: a systematic review and meta-analysis of observational studies. Int J Epidemiol. 2011;40:189-207.

13. Pasquali R, Casimirri F, Cantobelli S, Melchionda N, Morselli Labate AM, Fabbri R, et al. Effect of obesity and body fat distribution on sex hormones and insulin in men. Metabolism. 1991;40:101-4.

14. Khaw KT, Barrett-Connor E. Lower endogenous androgens predict central adiposity in men. Ann Epidemiol. 1992;2:675-82.

15. • Vaidya D, Dobs A, Gapstur SM, Golden SH, Cushman M, Liu K, et al. Association of baseline sex hormone levels with baseline and longitudinal changes in waist-to-hip ratio: multi-ethnic study of atherosclerosis. Int J Obes (Lond). 2012. doi:10.1038/ijo.2012.3. The authors demostrated the association between sex hormones and WHR at baseline and during the follow up. In particular, testosterone and SHBG correlates strongly with central adiposity and are predictor of future increase in adiposity.

16. Mohr BA, Bhasin S, Link CL, O'Donnell AB, McKinlay JB. The effect of changes in adiposity on testosterone levels in older men: longitudinal results from the massachusetts male aging study. Eur J Endocrinol. 2006;155:443-52.

17. Tajar A, Huhtaniemi IT, O'Neill TW, Finn JD, Pye SR, Lee DM, et al. Characteristics of androgen deficiency in late-onset hypogonadism: results from the european male aging study (emas). J Clin Endocrinol Metab. 2012;97:1508-16. 
18. Nielsen TL, Hagen C, Wraae K, Brixen K, Petersen PH, Haug E, et al. Visceral and subcutaneous adipose tissue assessed by magnetic resonance imaging in relation to circulating androgens, sex hormone-binding globulin, and luteinizing hormone in young men. J Clin Endocrinol Metab. 2007;92:2696-705.

19. Derby CA, Zilber S, Brambilla D, Morales KH, McKinlay JB. Body mass index, waist circumference and waist to hip ratio and change in sex steroid hormones: the massachusetts male ageing study. Clin Endocrinol (Oxf). 2006;65:125-31.

20. Tsai EC, Boyko EJ, Leonetti DL, Fujimoto WY. Low serum testosterone level as a predictor of increased visceral fat in japanese-american men. Int J Obes Relat Metab Disord. 2000; 24:485-91.

21. Araujo AB, O'Donnell AB, Brambilla DJ, Simpson WB, Longcope $\mathrm{C}$, Matsumoto AM, et al. Prevalence and incidence of androgen deficiency in middle-aged and older men: estimates from the massachusetts male aging study. J Clin Endocrinol Metab. 2004;89:5920-6.

22. Wu FC, Tajar A, Beynon JM, Pye SR, Silman AJ, Finn JD, et al. Identification of late-onset hypogonadism in middle-aged and elderly men. N Engl J Med. 2010;363:123-35.

23. Vermeulen A, Kaufman JM, Giagulli VA. Influence of some biological indexes on sex hormone-binding globulin and androgen levels in aging or obese males. J Clin Endocrinol Metab. 1996;81:1821-6.

24. Plymate SR, Matej LA, Jones RE, Friedl KE. Inhibition of sex hormone-binding globulin production in the human hepatoma (hep g2) cell line by insulin and prolactin. J Clin Endocrinol Metab. 1988;67:460-4.

25. Pugeat M, Crave JC, Elmidani M, Lejeune H, Charrie A, Fleury $\mathrm{MC}$, et al. inverse relationship between body mass index and fasting insulinemia with testosterone-binding protein in hirsutism. Ann Endocrinol (Paris). 1991;52:93-6.

26. Pitteloud N, Dwyer AA, DeCruz S, Lee H, Boepple PA, Crowley $\mathrm{Jr} \mathrm{WF}$, et al. The relative role of gonadal sex steroids and gonadotropin-releasing hormone pulse frequency in the regulation of follicle-stimulating hormone secretion in men. J Clin Endocrinol Metab. 2008;93:2686-92.

27. Bruning JC, Gautam D, Burks DJ, Gillette J, Schubert M, Orban $\mathrm{PC}$, et al. Role of brain insulin receptor in control of body weight and reproduction. Science. 2000;289:2122-5.

28. Gamba M, Pralong FP. Control of gnrh neuronal activity by metabolic factors: the role of leptin and insulin. Mol Cell Endocrinol. 2006;254-255:133-9.

29. Salvi R, Castillo E, Voirol MJ, Glauser M, Rey JP, Gaillard RC, et al. Gonadotropin-releasing hormone-expressing neurons immortalized conditionally are activated by insulin: implication of the mitogen-activated protein kinase pathway. Endocrinology. 2006;147:816-26.

30. Schneider G, Kirschner MA, Berkowitz R, Ertel NH. Increased estrogen production in obese men. J Clin Endocrinol Metab. 1979:48:633-8.

31. Giagulli VA, Kaufman JM, Vermeulen A. Pathogenesis of the decreased androgen levels in obese men. J Clin Endocrinol Metab. 1994;79:997-1000.

32. Pitteloud N, Dwyer AA, DeCruz S, Lee H, Boepple PA, Crowley $\mathrm{Jr} \mathrm{WF}$, et al. Inhibition of luteinizing hormone secretion by testosterone in men requires aromatization for its pituitary but not its hypothalamic effects: evidence from the tandem study of normal and gonadotropin-releasing hormone-deficient men. J Clin Endocrinol Metab. 2008;93:784-91.

33. Jones TM, Fang VS, Landau RL, Rosenfield R. Direct inhibition of leydig cell function by estradiol. J Clin Endocrinol Metab. 1978;47:1368-73.

34. Strain GW, Zumoff B, Miller LK, Rosner W, Levit C, Kalin M, et al. Effect of massive weight loss on hypothalamic-pituitary-gonadal function in obese men. J Clin Endocrinol Metab. 1988;66:1019-23.
35. Muller M, den Tonkelaar I, Thijssen JH, Grobbee DE, van der Schouw YT. Endogenous sex hormones in men aged 40-80years. Eur J Endocrinol. 2003;149:583-9.

36. Gautier A, Bonnet F, Dubois S, Massart C, Grosheny C, Bachelot $\mathrm{A}$, et al. Associations between visceral adipose tissue, inflammation and sex steroid concentrations in men. Clin Endocrinol (Oxf). 2012. doi:10.1111/j.1365-2265.2012.04401.x.

37. Zumoff B, Miller LK, Strain GW. Reversal of the hypogonadotropic hypogonadism of obese men by administration of the aromatase inhibitor testolactone. Metabolism. 2003;52:1126-8.

38. Ahima RS. Adipose tissue as an endocrine organ. Obesity (Silver Spring). 2006;14 Suppl 5:242S-9.

39. Ouchi N, Ohashi K, Shibata R, Murohara T. Adipocytokines and obesity-linked disorders. Nagoya J Med Sci. 2012;74:19-30.

40. Isidori AM, Caprio M, Strollo F, Moretti C, Frajese G, Isidori A, et al. Leptin and androgens in male obesity: evidence for leptin contribution to reduced androgen levels. J Clin Endocrinol Metab. 1999;84:3673-80.

41. Caprio M, Isidori AM, Carta AR, Moretti C, Dufau ML, Fabbri A. Expression of functional leptin receptors in rodent leydig cells. Endocrinology. 1999;140:4939-47.

42. Irwig MS, Fraley GS, Smith JT, Acohido BV, Popa SM, Cunningham $\mathrm{MJ}$, et al. Kisspeptin activation of gonadotropin releasing hormone neurons and regulation of kiss- 1 mrna in the male rat. Neuroendocrinology. 2004;80:264-72.

43. Luukkaa V, Pesonen U, Huhtaniemi I, Lehtonen A, Tilvis R, Tuomilehto J, et al. Inverse correlation between serum testosterone and leptin in men. J Clin Endocrinol Metab. 1998;83:3243-6.

44. Santos-Alvarez J, Goberna R, Sanchez-Margalet V. Human leptin stimulates proliferation and activation of human circulating monocytes. Cell Immunol. 1999;194:6-11.

45. Turer AT, Scherer PE. Adiponectin: mechanistic insights and clinical implications. Diabetologia. 2012. doi:10.1007/s00125-0122598-x.

46. Okamoto Y. Adiponectin provides cardiovascular protection in metabolic syndrome. Cardiol Res Pract. 2011;2011:313179.

47. Cnop M, Havel PJ, Utzschneider KM, Carr DB, Sinha MK, Boyko EJ, et al. Relationship of adiponectin to body fat distribution, insulin sensitivity and plasma lipoproteins: evidence for independent roles of age and sex. Diabetologia. 2003;46:459-69.

48. Page ST, Herbst KL, Amory JK, Coviello AD, Anawalt BD, Matsumoto AM, et al. Testosterone administration suppresses adiponectin levels in men. J Androl. 2005;26:85-92.

49. Watanobe H, Hayakawa Y. Hypothalamic interleukin-1 beta and tumor necrosis factor-alpha, but not interleukin-6, mediate the endotoxin-induced suppression of the reproductive axis in rats. Endocrinology. 2003;144:4868-75.

50. Russell SH, Small CJ, Stanley SA, Franks S, Ghatei MA, Bloom SR. The in vitro role of tumour necrosis factor-alpha and interleukin-6 in the hypothalamic-pituitary gonadal axis. J Neuroendocrinol. 2001;13:296-301.

51. Guzik TJ, Mangalat D, Korbut R. Adipocytokines - novel link between inflammation and vascular function? J Physiol Pharmacol. 2006;57:505-28.

52. Gonzalez-Santos MR, Gaja-Rodriguez OV, Alonso-Uriarte R, Sojo-Aranda I, Cortes-Gallegos V. Sleep deprivation and adaptive hormonal responses of healthy men. Arch Androl. 1989;22:203-7.

53. Penev PD. Association between sleep and morning testosterone levels in older men. Sleep. 2007;30:427-32.

54. Gambineri A, Pelusi C, Pasquali R. Testosterone levels in obese male patients with obstructive sleep apnea syndrome: relation to oxygen desaturation, body weight, fat distribution and the metabolic parameters. J Endocrinol Invest. 2003;26:493-8.

55. Pasquali R, Vicennati V, Gambineri A, Pagotto U. Sex-dependent role of glucocorticoids and androgens in the pathophysiology of human obesity. Int J Obes (Lond). 2008;32:1764-79. 
56. Fanelli F, Belluomo I, Di Lallo VD, Cuomo G, De Iasio R, Baccini $\mathrm{M}$, et al. Serum steroid profiling by isotopic dilution-liquid chromatography-mass spectrometry: comparison with current immunoassays and reference intervals in healthy adults. Steroids. 2011;76:244-53.

57. Bhasin S, Cunningham GR, Hayes FJ, Matsumoto AM, Snyder PJ, Swerdloff RS, et al. Testosterone therapy in men with androgen deficiency syndromes: an endocrine society clinical practice guideline. J Clin Endocrinol Metab. 2010;95:2536-59.

58. Halmenschlager G, Rhoden EL, Riedner CE. Calculated free testosterone and radioimmunoassay free testosterone as a predictor of subnormal levels of total testosterone. Int Urol Nephrol. 2012;44:673-81.

59. Bhasin S, Zhang A, Coviello A, Jasuja R, Ulloor J, Singh R, et al. The impact of assay quality and reference ranges on clinical decision making in the diagnosis of androgen disorders. Steroids. 2008;73:1311-7.

60. •- Ohlsson C, Wallaschofski H, Lunetta KL, Stolk L, Perry JR, Koster A, et al. Genetic determinants of serum testosterone concentrations in men. PLoS Genet. 2011;7:e1002313. The authors showed that genetic variants in the SHBG gene and on the $X$ chormosome arre associated with variation in testosterone concentrations and therefore suggesting the possibility to identify men at risk of low serum testosterone levels.

61. Stellato RK, Feldman HA, Hamdy O, Horton ES, McKinlay JB. Testosterone, sex hormone-binding globulin, and the development of type 2 diabetes in middle-aged men: prospective results from the massachusetts male aging study. Diabetes Care. 2000;23: 490-4.

62. Haffner SM, Shaten J, Stern MP, Smith GD, Kuller L. Low levels of sex hormone-binding globulin and testosterone predict the development of non-insulin-dependent diabetes mellitus in men. Mrfit research group. Multiple risk factor intervention trial. Am J Epidemiol. 1996;143:889-97.

63. Kupelian V, Page ST, Araujo AB, Travison TG, Bremner WJ, McKinlay JB. Low sex hormone-binding globulin, total testosterone, and symptomatic androgen deficiency are associated with development of the metabolic syndrome in nonobese men. J Clin Endocrinol Metab. 2006;91:843-50.

64. Laaksonen DE, Niskanen L, Punnonen K, Nyyssonen K, Tuomainen $\mathrm{TP}$, Valkonen VP, et al. Testosterone and sex hormone-binding globulin predict the metabolic syndrome and diabetes in middle-aged men. Diabetes Care. 2004;27:1036-41.

65. Oh JY, Barrett-Connor E, Wedick NM, Wingard DL, Rancho Bernardo S. Endogenous sex hormones and the development of type 2 diabetes in older men and women: the rancho bernardo study. Diabetes Care. 2002;25:55-60.

66. Ding EL, Song Y, Malik VS, Liu S. Sex differences of endogenous sex hormones and risk of type 2 diabetes: a systematic review and meta-analysis. JAMA. 2006;295:1288-99.

67. Haring R, Volzke H, Felix SB, Schipf S, Dorr M, Rosskopf D, et al. Prediction of metabolic syndrome by low serum testosterone levels in men: results from the study of health in pomerania. Diabetes. 2009;58:2027-31.

68. Selvin E, Feinleib M, Zhang L, Rohrmann S, Rifai N, Nelson WG, et al. Androgens and diabetes in men: results from the third national health and nutrition examination survey (nhanes iii). Diabetes Care. 2007;30:234-8.

69. Muller M, Grobbee DE, den Tonkelaar I, Lamberts SW, van der Schouw YT. Endogenous sex hormones and metabolic syndrome in aging men. J Clin Endocrinol Metab. 2005;90:2618-23.

70. Khaw KT, Dowsett M, Folkerd E, Bingham S, Wareham N, Luben $\mathrm{R}$, et al. Endogenous testosterone and mortality due to all causes, cardiovascular disease, and cancer in men: European prospective investigation into cancer in norfolk (epic-norfolk) prospective population study. Circulation. 2007;116:2694-701.
71. Yeap BB, Hyde Z, Almeida OP, Norman PE, Chubb SA, Jamrozik $\mathrm{K}$, et al. Lower testosterone levels predict incident stroke and transient ischemic attack in older men. J Clin Endocrinol Metab. 2009;94:2353-9.

72. Hyde Z, Norman PE, Flicker L, Hankey GJ, Almeida OP, McCaul $\mathrm{KA}$, et al. Low free testosterone predicts mortality from cardiovascular disease but not other causes: the health in men study. J Clin Endocrinol Metab. 2012;97:179-89.

73. Vikan T, Schirmer H, Njolstad I, Svartberg J. Endogenous sex hormones and the prospective association with cardiovascular disease and mortality in men: the tromso study. Eur J Endocrinol. 2009; 161:435-42.

74. Svartberg J, von Muhlen D, Mathiesen E, Joakimsen O, Bonaa $\mathrm{KH}$, Stensland-Bugge E. Low testosterone levels are associated with carotid atherosclerosis in men. J Intern Med. 2006;259:57682.

75. Fukui M, Kitagawa Y, Nakamura N, Kadono M, Mogami S, Hirata $\mathrm{C}$, et al. Association between serum testosterone concentration and carotid atherosclerosis in men with type 2 diabetes. Diabetes Care. 2003;26:1869-73.

76. De Pergola G, Pannacciulli N, Ciccone M, Tartagni M, Rizzon P, Giorgino R. Free testosterone plasma levels are negatively associated with the intima-media thickness of the common carotid artery in overweight and obese glucose-tolerant young adult men. Int J Obes Relat Metab Disord. 2003;27:803-7.

77. Malkin CJ, Pugh PJ, Morris PD, Asif S, Jones TH, Channer KS. Low serum testosterone and increased mortality in men with coronary heart disease. Heart. 2010;96:1821-5.

78. Muller M, van den Beld AW, Bots ML, Grobbee DE, Lamberts SW, van der Schouw YT. Endogenous sex hormones and progression of carotid atherosclerosis in elderly men. Circulation. 2004;109:2074-9.

79. Laughlin GA, Barrett-Connor E, Bergstrom J. Low serum testosterone and mortality in older men. J Clin Endocrinol Metab. 2008;93:68-75.

80. Kaukua J, Pekkarinen T, Sane T, Mustajoki P. Sex hormones and sexual function in obese men losing weight. Obes Res. 2003;11:689 94.

81. Khoo J, Piantadosi C, Worthley S, Wittert GA. Effects of a lowenergy diet on sexual function and lower urinary tract symptoms in obese men. Int J Obes (Lond). 2010;34:1396-403.

82. Pasquali R, Casimirri F, Melchionda N, Fabbri R, Capelli M, Plate $\mathrm{L}$, et al. Weight loss and sex steroid metabolism in massively obese man. J Endocrinol Invest. 1988;11:205-10.

83. Stanik S, Dornfeld LP, Maxwell MH, Viosca SP, Korenman SG. The effect of weight loss on reproductive hormones in obese men. J Clin Endocrinol Metab. 1981;53:828-32.

84. Hammoud A, Gibson M, Hunt SC, Adams TD, Carrell DT, Kolotkin RL, et al. Effect of roux-en-y gastric bypass surgery on the sex steroids and quality of life in obese men. J Clin Endocrinol Metab. 2009;94:1329-32.

85. Woodard G, Ahmed S, Podelski V, Hernandez-Boussard T, Presti Jr J, Morton JM. Effect of roux-en-y gastric bypass on testosterone and prostate-specific antigen. $\mathrm{Br} \mathrm{J}$ Surg. 2012;99:693-8.

86. Pasquali R, Macor C, Vicennati V, Novo F, De lasio R, Mesini P, et al. Effects of acute hyperinsulinemia on testosterone serum concentrations in adult obese and normal-weight men. Metabolism. 1997;46:526-9.

87. Niskanen L, Laaksonen DE, Punnonen K, Mustajoki P, Kaukua J, Rissanen A. Changes in sex hormone-binding globulin and testosterone during weight loss and weight maintenance in abdominally obese men with the metabolic syndrome. Diabetes Obes Metab. 2004;6:208-15.

88. Olivares A, Mendez JP, Zambrano E, Cardenas M, Tovar A, PereraMarin $\mathrm{G}$, et al. Reproductive axis function and gonadotropin 
microheterogeneity in a male rat model of diet-induced obesity. Gen Comp Endocrinol. 2010;166:356-64.

89. Palmer NO, Bakos HW, Owens JA, Setchell BP, Lane M. Diet and exercise in an obese mouse fed a high-fat diet improve metabolic health and reverse perturbed sperm function. Am J Physiol Endocrinol Metab. 2012;302:E768-80.

90. Hoffer LJ, Beitins IZ, Kyung NH, Bistrian BR. Effects of severe dietary restriction on male reproductive hormones. J Clin Endocrinol Metab. 1986;62:288-92.

91. Leenen R, van der Kooy K, Seidell JC, Deurenberg P, Koppeschaar HP. Visceral fat accumulation in relation to sex hormones in obese men and women undergoing weight loss therapy. J Clin Endocrinol Metab. 1994;78:1515-20.

92. Snyder PJ, Peachey H, Berlin JA, Hannoush P, Haddad G, Dlewati A, et al. Effects of testosterone replacement in hypogonadal men. J Clin Endocrinol Metab. 2000;85:2670-7.

93. Smith MR. Obesity and sex steroids during gonadotropin-releasing hormone agonist treatment for prostate cancer. Clin Cancer Res. 2007; 13:241-5.

94. Bhasin S, Taylor WE, Singh R, Artaza J, Sinha-Hikim I, Jasuja R, et al. The mechanisms of androgen effects on body composition: mesenchymal pluripotent cell as the target of androgen action. J Gerontol A Biol Sci Med Sci. 2003;58: M1103-10.

95. Singh R, Artaza JN, Taylor WE, Braga M, Yuan X, GonzalezCadavid NF, et al. Testosterone inhibits adipogenic differentiation in 3t3-11 cells: nuclear translocation of androgen receptor complex with beta-catenin and t-cell factor 4 may bypass canonical wnt signaling to down-regulate adipogenic transcription factors. Endocrinology. 2006;147:141-54.

96. Marin P, Holmang S, Gustafsson C, Jonsson L, Kvist H, Elander A, et al. Androgen treatment of abdominally obese men. Obes Res. 1993;1:245-51.

97. Marin P, Holmang S, Jonsson L, Sjostrom L, Kvist H, Holm G, et al. The effects of testosterone treatment on body composition and metabolism in middle-aged obese men. Int J Obes Relat Metab Disord. 1992;16:991-7.

98. Allan CA, McLachlan RI. Androgens and obesity. Curr Opin Endocrinol Diabetes Obes. 2010;17:224-32.

99. • Saad F, Aversa A, Isidori AM, Gooren LJ. Testosterone as potential effective therapy in treatment of obesity in men with testosterone deficiency: a review. Curr Diabetes Rev. 2012;8:131-43. The authors extensively revised all the studies in which testosterone treatment effect body composition. 